\title{
Complement C3 Expression Is Decreased in Autism Spectrum Disorder Subjects and Contributes to Behavioral Deficits in Rodents
}

\author{
Kiley Fagan ${ }^{a}$ Amanda Crider ${ }^{b}$ Anthony O. Ahmed ${ }^{c}$ Anilkumar Pillai ${ }^{b}$ \\ ${ }^{a}$ Medical College of Georgia, Augusta University, and ${ }^{b}$ Department of Psychiatry and Health Behavior, Augusta \\ University, Augusta, GA, and ${ }^{\mathrm{C}}$ Department of Psychiatry, Weill Cornell Medical College, White Plains, NY, USA
}

\section{Keywords}

Complement system · Autism spectrum disorder · Immune system · Behavior $\cdot$ Rodents interaction deficits and repetitive behavior in mice. Together, these studies suggest a potential role of $C 3$ in the pathophysiology of ASD.

(C) 2017 S. Karger AG, Basel

\begin{abstract}
Autism spectrum disorder (ASD) is a neurodevelopmental disorder with hallmark symptoms including social deficits, communication deficits and repetitive behaviors. Accumulating evidence suggests a potential role of the immune system in the pathophysiology of ASD. The complement system represents one of the major effector mechanisms of the innate immune system, and regulates inflammation, and orchestrates defense against pathogens. However, the role of CNS complement system in ASD is not well understood. In the present study, we found a significant increase in $\mathrm{C} 2, \mathrm{C} 5$, and MASP1, but a decrease in C1q, C3, and C4 mRNA levels in the middle frontal gyrus of ASD subjects compared to controls. Significant decreases in the mRNA levels of 2 key proinflammatory cytokines, IL-17 and IL-23 were observed in ASD subjects. Our study further demonstrated a strong association of complement genes with IL-17 and IL-23, suggesting a possible role of the complement system in immune dysregulation in ASD. We observed significant associations between complement components and abnormality of development scores in subjects with ASD. In rodents, C3 knockdown in the prefrontal cortex induced social
\end{abstract}

(C) 2017 S. Karger AG, Basel

\section{Introduction}

Autism spectrum disorder (ASD) is a complex set of neurodevelopmental disorders including pervasive developmental disorder not otherwise specified, Rett syndrome, Asperger syndrome, and autism [1, 2]. It is estimated that the prevalence of ASD is $1 \%$ of the population worldwide, with an occurrence of about 1 in 68 children in the US $[3,4]$. Symptoms of ASD include repetitive or stereotyped movements, cognitive impairments, deficiencies in communication and social interaction, speech impairments, and obsessive compulsive tendencies [5]. The exact pathophysiology of ASD is unknown; however, there are theories with regard to neurotransmitters, sex hormones, genetics, environmental factors, the stress response pathway, the immune system, and many other areas $[1,3,5,6]$.

An emerging area of research is the effect of the immune system on the central nervous system due to the

Kiley Fagan and Amanda Crider are co-first authors.

Anilkumar Pillai, $\mathrm{PhD}$

Department of Psychiatry and Health Behavior

Augusta University

Augusta, GA 30912 (USA)

E-Mail apillai@ augusta.edu 
fact that some genes regulate both brain development and immune function [5]. Relatives of people with autism as well as autistic patients have high rates of autoimmune diseases [6]. Many immune cells including lymphocytes and microglia as well as proteins that influence neuronal proliferation and survival such as cytokines, neuroinflammatory markers, and immunoglobulins have been found to be altered in autistic patients $[2,7]$. Specifically, TNF- $\alpha$, IL- $1 \beta$, and IL- 6 have been shown to be increased in blood, brain, and CSF from children with ASD [2]. There are also increased levels of complement proteins and MHC molecules in the plasma of ASD patients [2]. These changes in immune function in autism could be due to genetic factors or to the activation of the maternal immune system during pregnancy [2].

The immune system consists of the adaptive immune system and innate immune system. The complement system represents one of the major effector mechanisms of the innate immune system and serves to signal for more inflammation and clear cell debris and pathogens. The complement system consists of a number of inactive components that are activated in a cascade-like manner to exert its biological effects in the innate immune system. The complement cascade can be initiated by 3 major pathways: classical pathway, lectin pathway, and alternate pathway $[8,9] . \mathrm{C} 1 \mathrm{q}$ is the recognition molecule of the classical pathway and its binding to antigens or antibodies can activate the associated serine proteases $\mathrm{C} 1 \mathrm{r}$ and $\mathrm{C} 1 \mathrm{~s}$, leading to $\mathrm{C} 2$ and $\mathrm{C} 4$ cleavage to generate the $\mathrm{C} 3$ convertase, $\mathrm{C} 3 \mathrm{~b} 2 \mathrm{~b}$, which in turn cleaves $\mathrm{C} 3$ and activates downstream cascade components $[8,10,11]$. The lectin pathway is initiated by the binding of mannose-binding lectin (MBL) to mannose residues on the cell surface [8]. This activates the MBL-associated proteases MBL serine protease 1 (MASP1) and MASP2, which then cleave C4 to generate the $\mathrm{C} 4$ convertase, $\mathrm{C} 4 \mathrm{~b} 2 \mathrm{~b}$ [9]. The alternative pathway is activated by a "tickover" mechanism (via C3 hydrolysis), which functions primarily as an amplification loop of $\mathrm{C} 3 \mathrm{~b}$ after initiation by the classical pathway and the lectin pathway [9]. All 3 pathways converge on the major complement component, $\mathrm{C} 3$ leading to its activation. This activates microglia to release inflammatory signals, induces phagocytosis of the pathogens, and activates $\mathrm{T}$ cells which create cytokines including interleukins $[8,11]$.

Complement proteins in the blood are unable to cross the blood brain barrier (BBB) unless it is damaged [12, 13]. The brain produces complement proteins locally, so peripheral and central complement production remains isolated. In the CNS, complement proteins are expressed in neurons and glial cells [14]. Recent studies have shown that the classical complement cascade plays an important role in synaptic plasticity $[10,11,15,16]$.

In response to complement system activation, interleukins are synthesized and released [17]. Interleukin-17 (IL-17)-secreting CD4+ T cells (Th17 cells) are the key immune cells responsible for immune responses against infections. Th17 cells, cytokines, and interleukins play important roles in ASD [18]. Increased levels of IL-17 have been found in blood from subjects with ASD [19]. IL-23 has been shown to promote the terminal differentiation and expansion of Th17 effector cells, and is low in the peripheral blood of autistic patients [20]. However, it is not known whether IL-17 and IL-23 levels are altered in the brain of ASD subjects.

Despite the fact that inflammation is known to be a part of ASD pathophysiology, the role of the complement system in the brain of ASD subjects has never been explored. In the present study, we examined the expression of C1q, C2, C3, C4, C5, and MASP1, the main components of classical, lectin, and alternate pathways in the postmortem middle frontal gyrus of ASD and age and gender-matched control subjects. We also measured IL17, IL-23, and IL-10 mRNA in these subjects. In addition, we examined whether altered C3 expression in PFC induces behavioral deficits in mice.

\section{Methods}

\section{Ethics Statement}

The Augusta University Institutional Review Board has deemed this study exempt from full review due to the use of de-identified human postmortem brain samples, with no possibility to track back the identity of the donors. Human postmortem samples are from the NICHD Brain and Tissue Bank for Developmental Disorders at the University of Maryland with ethical permission granted by the institutional review boards of the University of Maryland. Animal studies were carried out in compliance with the US National Institute of Health guidelines and approved by Augusta University animal welfare guidelines.

Animals

Adult (8- to 10-week-old) C57BL/6J male mice were purchased from Charles River Laboratories (Wilmington, MA, USA). Mice were housed in groups of 4 mice in standard polypropylene cages in a 12-h light-dark cycle.

\section{Stereotaxic Injection of Lentivirus}

C3 shRNA (m) lentiviral (LV) particles and its control shRNA LV particles were purchased from Santa Cruz Biotechnology (Santa Cruz, CA, USA). LV-C3-shRNA is a pool of concentrated, transduction-ready viral particles containing 3 target-specific constructs that encode 19-25 nt (plus hairpin) shRNA designed to knock down gene expression. shRNA LV particles frozen stock contains a concentration of $1.0 \times 10^{6}$ infectious units of virus in
20

Mol Neuropsychiatry 2017;3:19-27

DOI: $10.1159 / 000465523$
Fagan/Crider/Ahmed/Pillai 
Table 1. Comparison of ASD and control samples

\begin{tabular}{lcccc}
\hline Covariate & Control & ASD & $F(1,23)$ & $p$ \\
\hline Age, years & $12.22(5.63)$ & $11.80(5.80)$ & 0.03 & 0.856 \\
PMI, h & $14.25(8.14)$ & $19.00(10.01)$ & 1.68 & 0.208 \\
Storage time, days & $3,997.08(2,143.47)$ & $2,828.77(1,434.07)$ & 2.60 & 0.120 \\
pH & $5.98(0.22)$ & $6.11(0.26)$ & 2.47 & 0.129 \\
RNA integrity & $5.78(2.52)$ & $6.84(1.92)$ & 1.40 & 0.248 \\
\hline
\end{tabular}

Data are presented as mean (SD). PMI, postmortem interval; RNA integrity range: 2.4-9.2.

Dulbecco's Modified Eagle's Medium with 25 mM HEPES pH 7.3. Mice (6-8 per group) were injected bilaterally with $5 \mu \mathrm{L}$ (each side) of LV particles into PFC by stereotaxic microinjection (coordinates: $x 0.5 \mathrm{~mm}$ [lateral], $y 1.0 \mathrm{~mm}$ [anterior-posterior], with respect to bregma at 0$), z 1.0 \mathrm{~mm}$ (dorsoventral with brain surface at 0 ) at a rate of $0.2 \mu \mathrm{L} / \mathrm{min}$ at each site (Stoelting Co).

\section{Behavior Experiments}

Behavioral testing was performed in a room with constant background sound and ambient lighting approximately 25-30 lux (lumen $/ \mathrm{m}^{2}$ ) unless noted. Temperature and pressure in behavioral rooms are monitored and kept constant. Animals are transferred in their home cages to behavioral rooms at least $1 \mathrm{~h}$ before testing and allowed to habituate to the testing room. All behavioral experiments were scored blind to treatment.

\section{Three Chamber Test}

This test was performed to measure sociability and social deficits. The test mouse was placed in a box with 3 chambers. Each chamber is $19 \times 45 \times 22 \mathrm{~cm}$, and the dividing walls are made from clear Plexiglas ${ }^{\circledR}$, with openings on each wall for free access to the other 2 chambers. Two identical wire containers that were large enough to house a single mouse were placed vertically inside the apparatus with one in each side chamber and weighted down. The test mouse was habituated to the apparatus for $5 \mathrm{~min}$ while freely exploring. After the habituation period, the stranger mouse was placed in one of the wire containers while the test mouse was still allowed to freely move outside of the container. The wire containers allow air exchange between the interior and exterior, but the holes are small enough to prevent direct physical contact between the stranger mouse and test mouse. The free test mouse was allowed to interact through the wire container with the stranger mouse for $5 \mathrm{~min}$. During this time, time spent in chambers (stranger mouse, empty cage, and center) was recorded by an examiner with a stopwatch. The stranger mouse chamber is defined as the chamber containing the wire container with the stranger mouse inside. The empty cage chamber is the chamber containing an empty wire container. The stranger mouse was a mouse of similar age, same sex, and similar weight as the test mouse.

Reciprocal Social Interaction Test

The test mouse was placed in a neutral box $(57 \times 45 \times 22 \mathrm{~cm})$ made from clear Plexiglas and allowed to habituate for $5 \mathrm{~min}$. After habituation, a stranger mouse was placed in the box and the test mouse was allowed to freely interact with the stranger mouse. In- teraction is defined as close physical contact, nose to nose sniffing, anogenital sniffing, and grooming. Time spent interacting (initiated by the test mouse) was recorded by an examiner with a stopwatch. The stranger mouse was a mouse of similar age, same sex, and similar weight as the test mouse.

\section{Marble Burying Test}

Each mouse was placed alone in a lidded standard polypropylene cage with approximately 2 inches of woodchip bedding and 10 equidistantly placed marbles, all of the same size and texture. The test mouse was left undisturbed in the cage for $30 \mathrm{~min}$ and allowed to freely move about the cage and dig in the bedding. The number of buried marbles out of the total of 10 was counted by the examiner. This test serves as another measure of repetitive behavior.

\section{Open Field Test}

Mouse activity in an open field chamber was measured over a 15 -min period. The open field chamber was $40 \times 40 \times 40 \mathrm{~cm}$ and made of white opaque Plexiglas. A video camera was fixed over the chamber by an adjacent rod. Ethovision XT 10 (Noldus Information Technologies Inc., USA) software was used for analysis. Trial totals for total distance travelled were taken.

\section{Ultrasonic Vocalizations}

Mice were habituated to the testing chamber for $5 \mathrm{~min}$, then introduced to an intruder mouse (stranger mouse of the similar age and weight as well as the same gender as the test mouse) for $5 \mathrm{~min}$. The intruder mouse was then removed from the testing chamber and the test mouse was recorded for $5 \mathrm{~min}$. The calls were recorded using Avisoft Recorder USGH (Avisoft Bioacoustics, Glienicke, Germany). The files were analyzed using SASLab Pro (Avisoft Bioacoustics), and Fast Fourier Transform (FFT) was performed using the following settings: sampling rate: $250 \mathrm{~Hz}$, FFTlength of 512 points, time window overlap of $75 \%$ (100\% frame hamming window). Frequency resolution was $488 \mathrm{~Hz}$, time resolution was $1 \mathrm{~ms}$, and the lower cutoff frequency was $20 \mathrm{kHz}$. Mean duration of calls, total duration of calls, mean peak amplitude, and vocalizations per minute were analyzed for each mouse, and group averages were plotted.

\section{Histology}

Mice were perfused transcardially with $4 \%$ (wt/vol) paraformaldehyde in $0.1 \mathrm{M}$ phosphate buffer $(\mathrm{PB})$. The brains were dissected and postfixed for $4 \mathrm{~h}$. Thereafter, tissue was incubated in $30 \%$ (wt/vol) sucrose/0.1 M PB. The brain tissue was cut into $20 \mu \mathrm{m}$ 
cryostat sections and stained using a TUNEL kit (ApopTag Fluorescein in situ Apoptosis Detection Kit; EMD Millipore, Temecula, CA, USA) as per the manufacturer's protocol.

\section{Human Postmortem Samples}

Postmortem middle frontal gyrus tissues were from ASD $(n=$ $13)$ and control $(n=12)$ subjects $[1,3,5]$. Demographic information is included in Table 1. Autism Diagnostic Interview-Revised (ADI-R) scores were available for 9 out of the 13 ASD subjects. There were no significant differences between tissues of ASD and control subjects in the areas of postmortem interval, refrigeration interval, age, RNA integrity, and brain $\mathrm{pH}$ (Table 1).

\section{Quantitative Reverse Transcriptase PCR}

The SV Total RNA Isolation System (Promega, Madison, WI, USA) was used to isolate mRNA. A SuperScript III Platinum SYBR Green One-Step qRT-PCR kit (Invitrogen, Carlsbad, CA, USA) was then used to perform qRT-PCR on a MasterCycler (Eppendorf, Hauppauge, NY, USA). Incubation was initiated at $55^{\circ} \mathrm{C}$ for $1,200 \mathrm{~s}$, then at $95^{\circ} \mathrm{C}$ for $120 \mathrm{~s}$ and preceded by 35 cycles at $95^{\circ} \mathrm{C}$ for $15 \mathrm{~s}, 50^{\circ} \mathrm{C}$ for $30 \mathrm{~s}, 72^{\circ} \mathrm{C}$ for $30 \mathrm{~s}$ for PCR amplification. Then, a melting curve was created from 55 to $95^{\circ} \mathrm{C}$ with $0.2^{\circ} \mathrm{C} / \mathrm{s}$. Each gene was normalized to a housekeeping gene (18S) for human samples. RPS3 was used as a housekeeping gene for mouse samples. Primer sequences are located in online supplementary Table 1 (see www.karger.com/doi/10.1159/000465523 for all online suppl. material).

\section{Statistical Analysis}

For mouse studies, data were analyzed using 2-tailed Student $t$ tests (for 2-group comparisons) or analysis of variance (ANOVA; for multiple-group comparisons). $p<0.05$ was considered significant. We used a multivariate analysis of covariance (MANCOVA) model to compare the postmortem samples of people with ASD with control samples on the expression of complement genes C1q, C2, C3, C4, C5, and MASP1 and cytokines IL-10, IL-17, and IL-23. The MANCOVA model served to evaluate and control for the effects of age, storage time, postmortem interval, $\mathrm{pH}$, and RNA integrity of the postmortem sample on measurements of gene expression. All covariates were included in the MANCOVA, and partial eta ${ }^{2}(\eta 2 p)$ was used to index effect size differences between ASD and control subjects. All analyses were completed using SPSS Statistics 20 software (IBM).

\section{Results}

The postmortem samples included those of 13 ASD subjects and 12 control subjects. There were no significant differences between the ASD group and control samples on any of the evaluated covariates. In the MANCOVA model, storage time (Wilk's $\lambda=0.422, F(6,13)=$ $2.965, p<0.05, \eta 2 \mathrm{p}=0.578$ ) and sample $\mathrm{pH}$ (Wilk's $\lambda=$ $0.426, F(6,13)=2.922, p=0.05, \eta 2 p=0.574)$ were significant predictors of complement gene expression. In contrast, none of the covariates significantly predicted the expression of interleukins.

\section{ASD Status and Complement Gene Expression}

In the overall multivariate model, there was a significant difference between ASD subjects and controls in complement gene expression (Wilk's $\lambda=0.009, F(6,13)=$ 238.11, $p<0.001, \eta 2 p=0.991$, observed power $=1.00$ ). An examination of the univariate between-subject effects showed that ASD status was associated with an increased expression of $\mathrm{C} 2(F(1,18)=19.41, p<0.0001, \eta 2 \mathrm{p}=0.52)$, $\mathrm{C} 5(F(1,18)=184.60, p<0.0001, \eta 2 \mathrm{p}=0.91)$, and MASP1 $(F(1,18)=198.39, p<0.0001, \eta 2 p=0.92)$ (Fig. 1). However, ASD was also associated with a decreased expression of C1q $(F(1,18)=520.82, p<0.0001, \eta 2 \mathrm{p}=0.97), \mathrm{C} 3(F(1$, $18)=306.49, p<0.0001, \eta 2 \mathrm{p}=0.95)$, and $\mathrm{C} 4(F(1,18)=$ 8.93, $p<0.01, \eta 2 p=0.332$ ) genes (Fig. 1).

\section{ASD Status and Inflammatory Cytokines}

The overall MANCOVA revealed significant differences between the postmortem samples of people with ASD and controls in the expression of interleukins (Wilk's $\lambda=0.011, F(3,16)=474.76, p<0.001, \eta 2 p=0.989, o b-$ served power $=1.00)$. The univariate between-subject analysis revealed that ASD status was especially associated with a decreased expression of IL-17 $(F(1,18)=$ $1,182.79, p<0.0001, \eta 2 \mathrm{p}=0.985)$ and IL-23 $(F(1,18)=$ $138.16, p<0.0001, \eta 2 \mathrm{p}=0.885)$ relative to control samples (Fig. 2). In contrast, there were no significant differences between ASD and control samples in the expression of IL-10 $(F(1,18)=1.81, p>0.05, \eta 2 p=0.092)$ (Fig. 2$)$.

Table 2 depicts the associations among complement genes and the expression of interleukins. In the ASD group, there was a significant negative association between C3 expression and the expression of IL-10. In contrast, more associations between complement genes and IL-17 and IL-23 were apparent in the complete sample including ASD and control samples.

The association of complement genes and interleukin expression with ASD features as measured by the ADI-R is given in Table 3. Whereas C1q, C3, and C4 had significant positive association with abnormality of development, C5 and MASP1 were negatively associated with abnormality of development. Of the interleukins, IL-17 and IL-23 were both significantly correlated with abnormality of development.

\section{C3 Inhibition in Mouse PFC Induces Social}

Interaction Deficits and Repetitive Behavior

Among the complement components, complement $\mathrm{C} 3$ is the convergence point of all activation pathways and the molecular hub for crosstalk with multiple pathogenic pathways. Therefore, we examined whether altering C3 


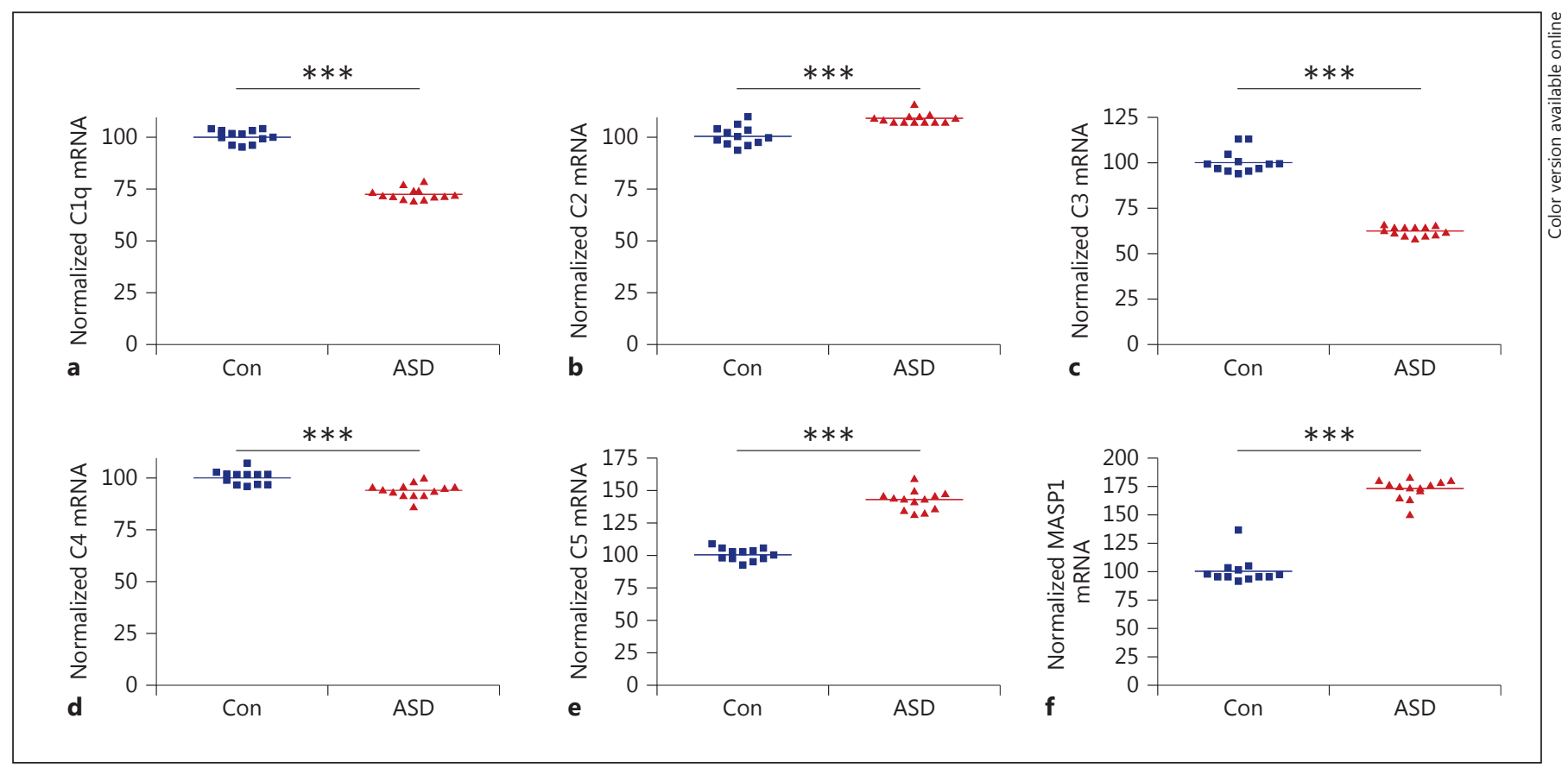

Fig. 1. C1q, C2, C3, C4, C5, and MASP1 mRNA levels in the middle frontal gyrus of ASD subjects. Levels of mRNA of complement proteins from the middle frontal gyrus of 12 controls and 13 ASD subjects were measured. C1q (a), C2 (b), C3 (c), C4 (d), C5 (e), and MASP1 (f) mRNA was normalized to the housekeeping gene 18S. Student $t$ tests were performed. ${ }^{* * *} p<0.0001$.

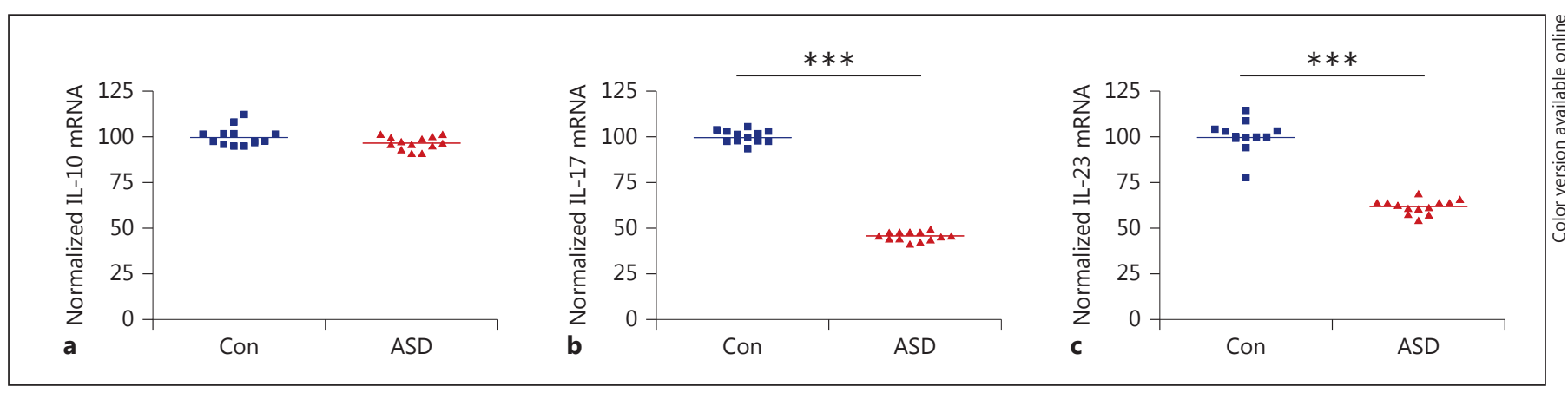

Fig. 2. IL-10, IL-17, and IL-23 mRNA levels in the middle frontal gyrus of ASD subjects. Levels of mRNA of IL10, IL-17, and IL-23 from the middle frontal gyrus of 12 controls and 13 ASD subjects were measured. IL-10 (a), IL-17 (b), and IL-23 (c) mRNA was normalized to 18S. Student $t$ tests were performed. ${ }^{* * *} p<0.0001$.

expression using a viral expression approach in PFC induces behavioral changes in mice. We found significant reduction in $\mathrm{C} 3 \mathrm{mRNA}$ levels in the $\mathrm{PFC}$ of mice given bilateral PFC infusion of C3 shRNA ( $p<0.05$; Fig. 3a). Next, we performed TUNEL assay to examine whether C3 depletion using shRNA in PFC induces any neuronal damage. No TUNEL-positive cells were detected in brain sections of mice injected with shRNA, which indicates

Complement System in Autism that $\mathrm{C} 3$ depletion in PFC does not induce any neuronal damage (Fig. 3b). In the 3-chamber test, we found that whereas control shRNA-injected mice spent more time in the chamber housing stranger mouse than the empty cage chamber, C3 shRNA-injected mice had no preference for either chamber $(p<0.05$; Fig. $3 c)$. In the reciprocal social interaction test, C3 shRNA-injected mice showed decreased interaction with a stranger mouse when com-

Mol Neuropsychiatry 2017;3:19-27 DOI: $10.1159 / 000465523$ 
Table 2. Correlations among complement gene and proinflammatory cytokines

\begin{tabular}{llllllllrr}
\hline & C1q & C2 & C3 & C4 & C5 & MASP1 & IL-10 & \multicolumn{1}{l}{ IL-17 } & IL-23 \\
\hline C1q & - & $-0.701^{* *}$ & $0.953^{* *}$ & $0.687^{* *}$ & $-0.938^{* *}$ & $-0.932^{* *}$ & 0.341 & $0.972^{* *}$ & $0.957^{* *}$ \\
C2 & -0.109 & - & $-0.741^{* *}$ & -0.396 & $0.818^{* *}$ & $0.810^{* *}$ & -0.162 & $-0.786^{* *}$ & $-0.698^{* *}$ \\
C3 & -0.029 & -0.223 & - & $0.646^{* *}$ & $-0.940^{* *}$ & $-0.933^{* *}$ & 0.300 & $0.967^{* *}$ & $0.931^{* *}$ \\
C4 & 0.293 & -0.232 & 0.172 & - & $-0.670^{* *}$ & $-0.548^{* *}$ & 0.302 & $0.677^{* *}$ & $0.646^{* *}$ \\
C5 & 0.032 & $0.789^{* *}$ & -0.237 & -0.249 & - & $0.917^{* *}$ & -0.340 & $-0.962^{* *}$ & $-0.895^{* *}$ \\
MASP1 & -0.210 & -0.070 & 0.515 & $0.636^{*}$ & -0.332 & - & -0.340 & $-0.959^{* *}$ & $-0.889^{* *}$ \\
IL-10 & -0.072 & -0.069 & $-0.637^{*}$ & -0.039 & 0.206 & -0.282 & - & 0.296 & 0.231 \\
IL-17 & 0.279 & -0.325 & 0.447 & 0.081 & -0.261 & 0.242 & -0.295 & - & $0.946^{* *}$ \\
IL-23 & 0.536 & 0.091 & 0.354 & -0.028 & 0.075 & 0.079 & -0.407 & $0.831^{* *}$ & - \\
\hline
\end{tabular}

Upper half represents correlations among complement genes and cytokines in the entire sample, whereas the lower half of the table represents correlations within the autism sample alone $(n=13) .{ }^{*} p<0.05$; ${ }^{* *} p<0.01$.

pared with those from control shRNA-treated group $(p<$ 0.05 ; Fig. $3 \mathrm{~d}$ ). In the marble burying test, the $\mathrm{C} 3$ shRNAinjected mice showed enhanced marble burying $(p<0.05$; Fig. 3e). We did not find any significant change in vocalizations per minute and total duration in the ultrasonic vocalization test between control and C3 shRNA-injected mice (Fig. 3f). There was no effect on distance traveled, indicating that locomotor activity was unaffected (Fig. 3g).

\section{Discussion}

Our data provide the first ever evidence of altered complement gene expression in the brain of subjects with ASD. One theory on the development of ASD is that inflammation during pregnancy of any of the maternal, neonatal, and fetal compartments leads to an increase of proinflammatory cytokines. This increase could result in abnormal brain development and the development of ASD [21]. Although a number of studies have shown increased levels of inflammatory cytokines in the offspring exposed to maternal viral infections $[22,23]$, the mechanism(s) leading to ASD-like phenotype is not known. Viral infection is known to activate all 3 pathways of the complement cascade [24]. Complement activation leads to a number of effector functions that contribute to virus inactivation and elimination. It is known that complement activation promotes phagocytosis, and enhancement of several arms of the immune response through the production of anaphylatoxins and chemotactic factors [24].

We found that C3 inhibition in PFC leads to social deficits and repetitive behavior in mice. In the CNS, com-
Table 3. Correlations of complement genes and interleukins with ADI-R scores

\begin{tabular}{lrrrrc}
\hline & ADI-A & ADI-BV & ADI-BNV & ADI-C & ADI-D \\
\hline C1q & 0.138 & -0.358 & 0.295 & 0.028 & $0.826^{*}$ \\
C2 & -0.043 & -0.458 & -0.593 & 0.277 & -0.469 \\
C3 & 0.212 & -0.304 & 0.302 & 0.037 & $0.887^{* *}$ \\
C4 & 0.068 & -0.216 & 0.422 & 0.025 & $0.822^{*}$ \\
C5 & -0.074 & 0.118 & -0.471 & 0.131 & $-0.777^{*}$ \\
MASP1 & -0.110 & 0.305 & -0.447 & 0.097 & $-0.830^{*}$ \\
IL-10 & 0.261 & -0.443 & 0.200 & -0.382 & 0.664 \\
IL-17 & 0.244 & -0.328 & 0.336 & -0.054 & $0.881^{* *}$ \\
IL-23 & 0.163 & -0.410 & 0.127 & 0.145 & $0.786^{*}$ \\
\hline
\end{tabular}

ADI-A, social interaction; ADI-BV, verbal communication; ADI-BNV, non-verbal communication; ADI-C, stereotyped behavior; ADI-D, abnormality of development. * $p<0.05$; ** $p<$ 0.01 .

plement proteins are widely expressed in neurons and glia [14]. C1q deficiency in mice resulted in decreased synapse loss, enhanced activity-dependent synaptic potentiation and an improvement in cognitive function [25, 26]. C1q is also important in neurodevelopment, specifically for synaptic elimination [10]. C3 tags weak or inactive synapses to signal to microglia for pruning, suggesting that $\mathrm{C} 3$ deficiency may limit the synaptic pruning process [14]. Interestingly, higher spine density in pyramidal neurons has been reported in the temporal cortex of ASD patients than in controls [27]. In addition, aged C3 knock out mice performed better on learning and memory tests than aged WT mice [28]. A recent study has
Fagan/Crider/Ahmed/Pillai 


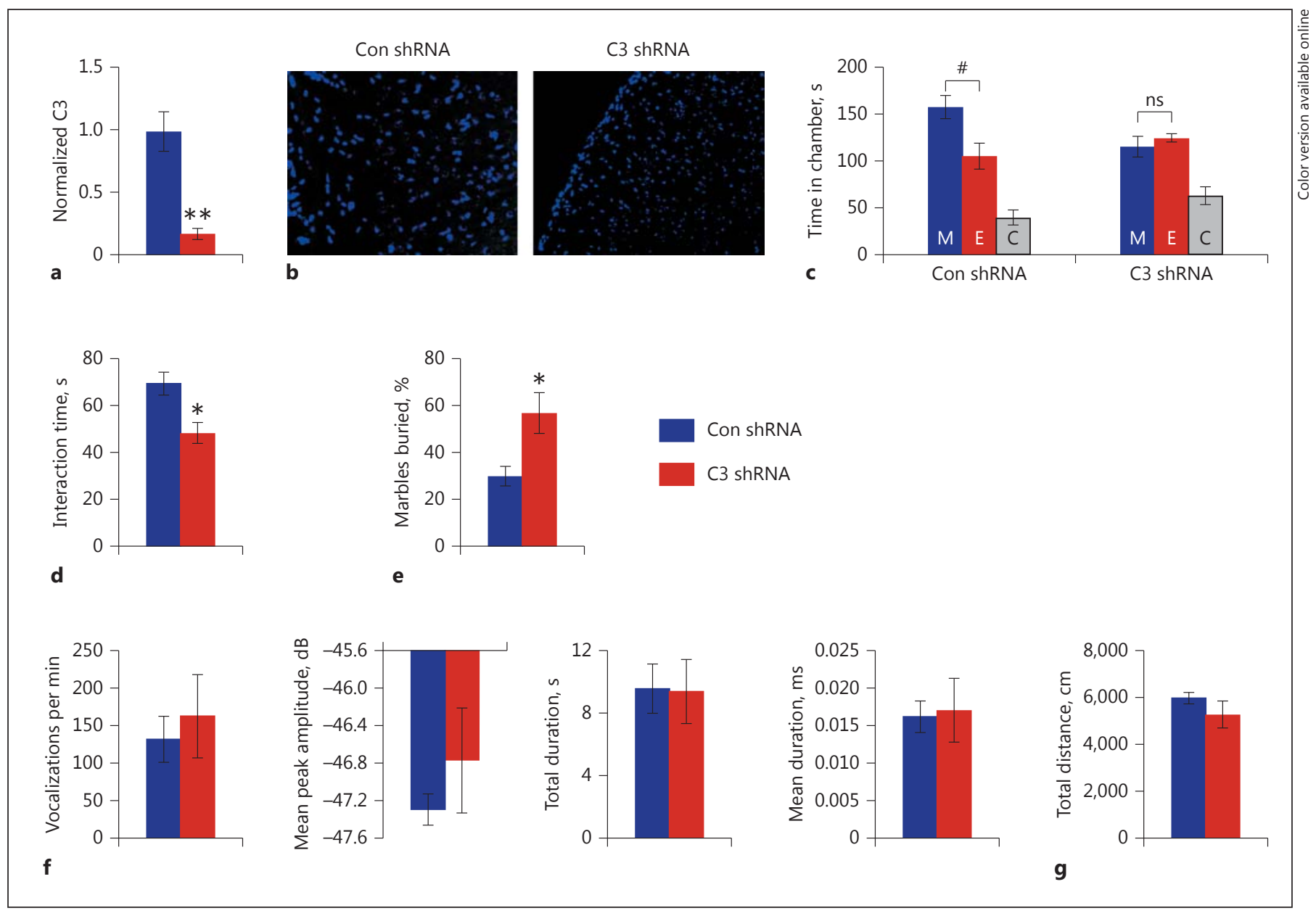

Fig. 3. Injection of C3 shRNA into PFC induces social interaction deficits and repetitive behavior in male mice. Adult male mice were injected with control or C3 shRNA lentiviral particles and allowed to recover for 2 weeks. a C3 mRNA in the PFC normalized to the housekeeping gene RPS3. b Representative images of TUNEL staining of the frontal cortex. $\mathbf{c}$ Three chamber test. M, stranger mouse; E, empty cage; C, center. $\mathbf{d}$ Social interaction test. e Marble bury test. $\mathbf{f}$ Ultrasonic vocalization recordings. $\mathbf{g}$ Open field test. $n=6-8$. $^{*} p<0.05$ and ${ }^{* *} p<0.01$ vs. control shRNA group; ${ }^{*} p<0.05$ vs. stranger mouse chamber; ns, not significant.

found increased C4 mRNA levels in postmortem brain samples from schizophrenia, and reduced synaptic pruning in mice lacking functional C4 [29]. These studies suggest that a number of complement proteins have diverse functions in the brain.

Despite an intense interest in inflammation in ASD, the role of CNS complement system in ASD has never been well explored. Warren et al. [30] found increased C4B alleles in autistic patients and their mothers. A few studies have reported altered levels of complement molecules in the periphery of subjects with ASD. For example, an increase in C1q levels has been shown in the plasma of children with ASD [31]. Higher levels of C3 and C3

Complement System in Autism fragments were also found in the plasma of children with ASD [32]. Moreover, complement factor I activity, a degradation factor of $\mathrm{C} 3$, was found to be higher in the plasma of ASD patients [33]. Overall, the above findings indicate increased activity of the complement system in the periphery of subjects with ASD.

In the present study, we found significant increases in mRNA levels of $\mathrm{C} 2, \mathrm{C} 5$, and MASP1 in the PFC of ASD subjects as compared to controls. However, the mRNA levels of $\mathrm{C} 1 \mathrm{q}, \mathrm{C} 3$, and $\mathrm{C} 4$ were significantly decreased in ASD subjects. The mechanism behind the above observed differential regulation of complement genes in the brain of ASD subjects is unknown. It is known that C3a and C5a 
enhance inflammation by activating mast cells which then release histamine as well as synthesize and release cytokines [17]. However, it is not clear whether the changes in the levels of complement molecules in the CNS correlate with peripheral changes. In traumatic brain injury, it has been shown that the majority of complement proteins in the brain are from the periphery due to the dysfunction of the BBB [34]. A number of studies suggest mast cell activation as a mechanism for BBB disruption and brain inflammation in ASD $[35,36]$. However, further studies are warranted to better understand the brain versus peripheral contribution of the complement system in ASD.

Complement components are known to enhance the production of cytokines [17, 37]. It is known that complement components regulate the effector function of activated $\mathrm{T}$ cells by regulating the development of Th1, Th2, and Th17 helper cells $[37,38]$. Th17 cells and their cytokine mediators have been suggested to have a role in ASD. Increased levels of IL-17 have been found in blood from subjects with ASD $[19,39,40]$. In the maternal immune activation (MIA) mouse model of ASD, systemic blockage of IL-17 inhibited the MIA-induced ASD-like behavior in the offspring, suggesting that IL-17 plays an important role during the pathophysiological process of ASD [41]. We found a significant decrease in IL-17 mRNA levels in the brain of ASD subjects. It is known that the production of IL-17A is reciprocally regulated by the anaphylatoxins with $\mathrm{C} 5$ a signaling limiting the frequency of Th17 cells, while C3a signaling enhanced Th17 responses [37]. Moreover, the opposing actions of C3 and C5 on IL$17 \mathrm{~A}$ were mediated via reciprocal regulation of dendritic cell (DC) IL-23 production [37]. In agreement with the above findings, we found a significant negative association of C5 with IL-17 and IL-23, but positive association of $\mathrm{C} 3$ with these interleukins in our samples. IL-17 being a proinflammatory cytokine, we expect to find an increase in IL-17 mRNA in the brain of ASD subjects. The observed decrease in IL-17 levels in the brain of ASD subjects is counter to the previously published results of increased IL-17 levels in the blood of subjects with ASD. Although the exact mechanism for a decrease in IL-17 mRNA is not known, further studies should investigate whether peripheral IL-17 through interacting with its receptor on endothelial cells could down regulate IL-17 synthesis in the PFC via a negative feedback mechanism.

In summary, the findings from this study provide the initial evidence on the role of the complement system in the CNS of ASD subjects. A limitation of this study is that Autism Diagnostic Interview-Revised was available for only 9 of the 13 ASD individuals, which needs further in- vestigation using large samples before a conclusion can be drawn. Previous studies have shown altered levels of complement proteins and interleukins in the periphery of ASD subjects, but no previous evidence was available on the status of the complement system in the brain of these subjects. It is important to note that although the complement system is typically deleterious to brain function, it is sometimes neuroprotective. For example, C5a has been shown to be neuroprotective against neurodegenerative excitotoxicity and apoptosis in neuronal cells [42]. The complement system is a potential target for drug development as it has a number of receptors that bind to different components of the innate immune system. A number of drugs targeting the complement system are currently being developed [43], suggesting the complement system may be a promising therapeutic target in ASD.

\section{Acknowledgements}

Human postmortem samples were obtained from the NICHD Brain and Tissue Bank for Developmental Disorders at the University of Maryland, Baltimore, MD, USA. The Bank is funded by NIH Contract No. \#HHSN275200900011C, Ref. No. NO1-HD9-0011. The authors would like to acknowledge the research support from US National Institute of Mental Health grant R01 MH 097060 (A.P.).

\section{Disclosure Statement}

There are no conflicts of interest to report.

References

1 Crider A, Thakkar R, Ahmed AO, Pillai A: Dysregulation of estrogen receptor beta $(\mathrm{ER} \beta)$, aromatase (CYP19A1), and ER co-activators in the middle frontal gyrus of autism spectrum disorder subjects. Mol Autism 2014;5:46.

2 Onore C, Careaga M, Ashwood P: The role of immune dysfunction in the pathophysiology of autism. Brain Behav Immun 2012;26:383392.

3 Crider A, Pandya CD, Peter D, Ahmed AO, Pillai A: Ubiquitin-proteasome dependent degradation of GABAA alphal in autism spectrum disorder. Mol Autism 2014;5:45.

4 Christensen DL, Bilder DA, Zahorodny W, Pettygrove S, Durkin MS, Fitzgerald RT, Rice C, Kurzius-Spencer M, Baio J, Yeargin-Allsopp M: Prevalence and characteristics of autism spectrum disorder among children aged 8 years - autism and developmental disabilities monitoring network. J Dev Behav Pediatr 2016;37:1-8.
26

Mol Neuropsychiatry 2017;3:19-27 DOI: $10.1159 / 000465523$
Fagan/Crider/Ahmed/Pillai 
5 Patel N, Crider A, Pandya CD, Ahmed AO, Pillai A: Altered mRNA levels of glucocorticoid receptor, mineralocorticoid receptor, and cochaperones (FKBP5 and PTGES3) in the middle frontal gyrus of autism spectrum disorder subjects. Mol Neurobiol 2016;53:2090-2099.

6 Ashwood P, Van De Water J: Is autism an autoimmune disease? Autoimmun Rev 2004;3: 557-562.

7 Randolph-Gips M, Srinivasan P: Modeling autism: a systems biology approach. J Clin Bioinforma 2012;1:17.

8 Sompayrac L: How the Immune System Works, ed 5. New York, Wiley, 2016.

9 Merle NS, Church SE, Fremeaux-Bacchi V, Roumenina LT: Complement system. I. Molecular mechanisms of activation and regulation. Front Immunol 2015;6:262.

10 Stevens B, Allen NJ, Vazquez LE, Howell GR, Christopherson KS, Nouri N, Micheva KD, Mehalow AK, Huberman AD, Stafford B, Sher A, Litke AM, Lambris JD, Smith SJ, John SW, Barres BA: The classical complement cascade mediates CNS synapse elimination. Cell 2007;131:1164-1178.

11 Fourgeaud L, Boulanger LM: Synapse remodeling, compliments of the complement system. Cell 2007;131:1034-1036.

12 Van Beek J, Elward K, Gasque P: Activation of complement in the central nervous system. Ann NY Acad Sci 2003;992:56-71.

13 Ashwood P, Van de Water J: A review of autism and the immune response. Clin Dev Immunol 2004;11:165-174.

14 Schafer DP, Lehrman EK, Kautzman AG, Koyama R, Mardinly AR, Yamasaki R, Ransohoff RM, Greenberg ME, Barres BA, Stevens B: Microglia sculpt postnatal neural circuits in an activity and complement-dependent manner. Neuron 2012;74:691-705.

15 Stephan AH, Barres BA, Stevens B: The complement system: an unexpected role in synaptic pruning during development and disease. Annu Rev Neurosci 2012;35:369-389.

16 Hong S, Beja-Glasser VF, Nfonoyim BM, Frouin A, Li S, Ramakrishnan S, Merry KM, Shi Q, Rosenthal A, Barres BA, Lemere CA, Selkoe DJ, Stevens B: Complement and microglia mediate early synapse loss in Alzheimer mouse models. Science 2016;352:712-716.

17 Markiewski MM, Lambris JD: The role of complement in inflammatory diseases from behind the scenes into the spotlight. Am J Pathol 2007;171:715-727.

18 Zimmerman AW, Jyonouchi H, Comi AM, Connors SL, Milstien S, Varsou A, Heyes MP: Cerebrospinal fluid and serum markers of inflammation in autism. Pediatr Neurol 2005; 33:195-201.

19 Akintunde ME, Rose M, Krakowiak P, Heuer L, Ashwood P, Hansen R, Hertz-Picciotto I, Van de Water J: Increased production of IL17 in children with autism spectrum disorders and co-morbid asthma. I Neuroimmunol 2015;286:33-41.
20 Onore C, Enstrom A, Krakowiak P, HertzPicciotto I, Hansen R, Van de Water J, Ashwood P: Decreased cellular IL-23 but not IL17 production in children with autism spectrum disorders. J Neuroimmunol 2009;216: 126-129.

21 Patterson PH: Maternal infection and immune involvement in autism. Trends $\mathrm{Mol}$ Med 2011;17:389-394.

22 Patterson PH: Maternal infection: window on neuroimmune interactions in fetal brain development and mental illness. Curr Opin Neurobiol 2002;12:115-118.

23 Brown AS: Epidemiologic studies of exposure to prenatal infection and risk of schizophrenia and autism. Dev Neurobiol 2012;72:12721276.

24 Blue CE, Spiller OB, Blackbourn DJ: The relevance of complement to virus biology. Virology 2004;319:176-184.

25 Fonseca MI, Zhou J, Botto M, Tenner AJ: Absence of C1q leads to less neuropathology in transgenic mouse models of Alzheimer's disease. J Neurosci 2004;24:6457-6465.

26 Stephan AH, Madison DV, Mateos JM, Fraser DA, Lovelett EA, Coutellier L, Kim L, Tsai HH, Huang EJ, Rowitch DH, Berns DS, Tenner AJ, Shamloo M, Barres BA: A dramatic increase of $\mathrm{Clq}$ protein in the CNS during normal aging. J Neurosci 2013;33:1346013474.

27 Tang G, Gudsnuk K, Kuo SH, Cotrina ML, Rosoklija G, Sosunov A, Sonders MS, Kanter E, Castagna C, Yamamoto A, Yue Z, Arancio O, Peterson BS, Champagne F, Dwork AJ, Goldman J, Sulzer D: Loss of mTOR-dependent macroautophagy causes autistic-like synaptic pruning deficits. Neuron 2014;83: 1131-1143.

28 Shi Q, Colodner KJ, Matousek SB, Merry K, Hong S, Kenison JE, Frost JL, Le KX, Li S, Dodart JC, Caldarone BJ, Stevens B, Lemere CA: Complement C3-deficient mice fail to display age-related hippocampal decline. J Neurosci 2015;35:13029-13042.

29 Sekar A, Bialas AR, de Rivera H, Davis A, Hammond TR, Kamitaki N, Tooley K, Presumey J, Baum M, Van Doren V, Genovese G, Rose SA, Handsaker RE; Schizophrenia Working Group of the Psychiatric Genomics Consortium, Daly MJ, Carroll MC, Stevens B, McCarroll SA: Schizophrenia risk from complex variation of complement component 4 . Nature 2016;530:177-183.

30 Warren RP, Singh VK, Cole P, Odell JD, Pingree $\mathrm{CB}$, Warren WL, White E: Increased frequency of the null allele at the complement C4b locus in autism. Clin Exp Immunol 1991; 83:438-440.

31 Corbett BA, Kantor AB, Schulman H, Walker WL, Lit L, Ashwood P, Rocke DM, Sharp FR: A proteomic study of serum from children with autism showing differential expression of apolipoproteins and complement proteins. Mol Psychiatry 2007;12:292-306.
32 Momeni N, Bergquist J, Brudin L, Behnia F, Sivberg B, Joghataei MT, Persson BL: A novel blood-based biomarker for detection of autism spectrum disorders. Transl Psychiatry 2012;2:e91

33 Momeni N, Brudin L, Behnia F, Nordström B, Yosefi-Oudarji A, Sivberg B, Joghataei MT, Persson BL: High complement factor I activity in the plasma of children with autism spectrum disorders. Autism Res Treat 2012:2012: $1-6$.

34 Vojdani A, Campbell AW, Anyanwu E, Kashanian A, Bock K, Vojdani E: Antibodies to neuron-specific antigens in children with autism: possible cross-reaction with encephalitogenic proteins from milk, Chlamydia pneumoniae and Streptococcus group A. J Neuroimmunol 2002;129:168-177.

35 Singer HS, Morris CM, Williams PN, Yoon DY, Hong JJ, Zimmerman AW: Anti-brain antibodies in children with autism and their unaffected siblings. J Neuroimmunol 2006; 178:149-155.

36 Orsini F, De Blasio D, Zangari R, Zanier ER, De Simoni MG: Versatility of the complement system in neuroinflammation, neurodegeneration and brain homeostasis. Front Cell Neurosci 2014;8:380.

37 Lajoie S, Lewkowich IP, Suzuki Y, Clark JR, Sproles AA, Dienger K, Budelsky AL, WillsKarp M: Complement-mediated regulation of the IL-17A axis is a central genetic determinant of the severity of experimental allergic asthma. Nat Immunol 2010;11:928-935.

38 Drouin SM, Corry DB, Kildsgaard J, Wetsel RA: Cutting edge: the absence of $\mathrm{C} 3$ demonstrates a role for complement in Th2 effector functions in a murine model of pulmonary allergy. J Immunol 2001;167:4141-4145.

39 Suzuki K, Matsuzaki H, Iwata K, Kameno Y, Shimmura C, Kawai S, Yoshihara Y, Wakuda T, Takebayashi K, Takagai S, Matsumoto K, Tsuchiya KJ, Iwata Y, Nakamura K, Tsujii M, Sugiyama T, Mori N: Plasma cytokine profiles in subjects with high-functioning autism spectrum disorders. PLoS One 2011;6:e20470.

40 Al-Ayadhi LY, Mostafa GA: Elevated serum levels of interleukin-17A in children with autism. J Neuroinflammation 2012;9:158.

41 Choi GB, Yim YS, Wong H, Kim S, Kim H, Kim SV, Hoeffer CA, Littman DR, Huh JR: The maternal interleukin-17a pathway in mice promotes autism-like phenotypes in offspring. Science 2016;351:933-939.

42 Osaka H, Mukherjee P, Aisen PS, Pasinetti GM: Complement-derived anaphylatoxin C5a protects against glutamate-mediated neurotoxicity. J Cell Biochem 1999;73:303311.

43 Morgan BP, Harris CL: Complement, a target for therapy in inflammatory and degenerative diseases. Nat Rev Drug Discov 2015;14:857877. 